\title{
Mercado de hortaliças frescas no município de Mineiros-GO
}

\author{
Mauro BD Tofanelli'; Marilaine de S Fernandes ${ }^{1,2}$; Oscar B Martins Filho²; Núbia S Carrijo² \\ ${ }^{1}$ Fimes-Instituto de Ciências Agrárias, C. Postal 104, 75830-000 Mineiros-GO; ${ }^{2}$ Fimes-Instituto de Dados Estatísticos e de Pesquisas \\ Sócio-Econômicas; maurobrasil@fimes.edu.br
}

\section{RESUMO}

A comercialização racional e eficiente de hortaliças necessita de estudos constantes nos mercados para fornecer informações que possam servir de suporte à elaboração de estratégias e execuções de ações para melhorias em todo contexto mercadológico. O presente trabalho teve como objetivo realizar levantamento do mercado de olerícolas in natura no município de Mineiros (Goiás) a fim de fornecer informações de mercado que possam auxiliar em ações específicas ao setor. Para isso, foram realizadas pesquisas em estabelecimentos comerciais (equipamentos varejistas: supermercados, quitandas e feira-livre) entre dezembro de 2005 e janeiro de 2006 mediante aplicação de questionários em cada equipamento. Dentre as hortaliças relacionadas pela pesquisa, o tomate, melancia, cebola e batata inglesa foram as comercializadas semanalmente em maior volume. Os resultados demonstraram que os supermercados e as quitandas são os principais responsáveis pelo comércio de olerícolas em Mineiros. Adeficiência na produção local de hortaliças em Mineiros pôde ser evidenciada, pois $81,8 \%$ dos produtos comercializados no município são oriundos de fornecedores distantes e apenas 18,2\% de produtores locais. O agronegócio olericultura em Mineiros é incapaz de servir ao município em suas necessidades.

Palavras-chave: Olerícolas, comercialização, mercado, olericultura.

\begin{abstract}
Fresh vegetables market in Mineiros, Goiás State, Brazil

Rational and efficient vegetable commercialization needs constant studies about markets to supply information which can support the elaboration of strategies and actions to improve all marketing context. The objective of this work was to carry out a survey about the fresh vegetable market in Mineiros, Goiás State, Brazil, in order to supply market information that may assist specific actions for the sector. For this, a research was carried out in commercial establishments (supermarkets, grocery stores and street market) from December 2005 to January 2006 by applying questionnaires in each establishment. Among the vegetables related in the research, tomato, watermelon, onion and potato were the ones commercialized weekly in higher volume. The results showed that supermarkets and grocery stores are the most responsible ones for the vegetable trade in Mineiros. The local vegetable production deficiency was evidenced when it was established that $81.8 \%$ of the products commercialized in the city are coming from distant suppliers and only $18.2 \%$ from local producers. The agribusiness of vegetables in Mineiros is incapable of supplying the city's necessities.
\end{abstract}

Keywords: Vegetables, commercialization, market, horticulture.

(Recebido para publicação em 31 de julho de 2006; aceito em 1 de agosto de 2007)

A s hortaliças são alimentos indispensáveis para a dieta equilibrada, pois são importantes fontes de vitaminas, sais minerais, carboidratos, fibras e outras substâncias como $\beta$-caroteno que contribuem, indiscutivelmente, para a saúde humana (Agrianual, 2000; Silva \& Naves, 2001; Filgueira, 2003; Campos et al., 2006). O Brasil é um grande produtor de hortaliças com um volume de produção de 16 milhões de toneladas em 2004 (Embrapa, 2006). Sobretudo, nem por isso o brasileiro é um grande consumidor destes vegetais, pois consumiu $43 \mathrm{~kg}$ em 2004 (FAO, 2007), seja pela má educação alimentar, pelas dificuldades no sistema de comercialização dos produtos olerícolas (venda /compra) que influenciam na oscilação dos preços e/ou pelo baixo poder aquisitivo do consumidor. Enquanto que em países desenvolvidos como Alemanha e Estados Unidos o consumo em 2004 foi de 139 e $127 \mathrm{~kg}_{\text {habitante }}{ }^{-1}$ ano $^{-1}$, respectivamente (FAO, 2007).

Neste tocante, o mercado é uma importante e complexa etapa entre a produção e o consumo das hortaliças, sendo definido pelos diversos canais de comercialização (distribuição) e deficiên- cias neste processo podem produzir efeitos gravemente indesejáveis. A sazonalidade de preços das hortaliças ao longo do ano em virtude das oscilações de mercado (oferta /procura) que quase sempre estão relacionadas com as variações climáticas e organização do sistema de comercialização (Filgueira, 2003), é vista como desvantajosa para o olericultor e o consumidor final. A elevação excessiva de preços dificulta o acesso ao consumidor final que às vezes deixa de consumir tal produto vegetal pelo acréscimo que este causaria no orçamento familiar. A comercialização das hortaliças é ainda mais complexa devido o alto índice de perecibilidade destes produtos (Vilela et al., 2003; Lourenzani \& Silva, 2004).

O conhecimento do canal de comercialização e a postura cooperativa baseada na transparente relação entre cada elo da cadeia conforme as características do produto e do mercado servem de ferramenta para melhor organização do contexto mediante, por exemplo, a entrega do produto no lugar adequado, no momento certo, na forma e quantidade desejadas e a criação de utilidades de posse, lugar, tempo e forma (Bueno et al., 1999; Fagundes
\& Yamanishi, 2002; Silva et al., 2003). Para Camargo Filho et al. (2001), o conhecimento do contexto mercadológico das hortaliças é tão importante que deve ser considerado até no planejamento de cultivo. Já Farina \& Machado, (1999) consideraram que estudar periodicamente os preços de compra e venda, bem como a margem de comercialização possibilita, por exemplo, a manipulação dos preços no varejo visando maior consumo e a manutenção dos lucros nos mercados.

O estado de Goiás tem participação mediana na produção de olerícolas no cenário nacional, pois ocupou a $12^{\mathrm{a}}$ posição no ranking brasileiro com um volume geral de 387 mil toneladas de hortaliças frescas produzidas em 1996 (IBGE, 2006b). O município de Mineiros localizado na região sudoeste de Goiás possui alguns nichos de olericultura; no entanto não é tradicional na produção destes vegetais em virtude, possivelmente, da predominância de outras atividades agropecuárias como as culturas de soja, milho, sorgo e algodão e a criação de gado. Isso se reflete na dependência do fornecimento de hortaliças vindas de outras regiões, o que contribui 
Tabela 1. Volume semanal de olerícolas frescas comercializadas no município de Mineiros-GO. (Fresh vegetable volume commercialized on city Mineiros). ICA/Fimes, Mineiros, 2006.

\begin{tabular}{|c|c|c|c|c|c|c|c|c|c|c|c|}
\hline \multicolumn{3}{|c|}{ Supermercados } & \multicolumn{3}{|c|}{$\begin{array}{c}\text { Equipamento } \\
\text { quitandas/sacolões }\end{array}$} & \multicolumn{3}{|c|}{ Feira-livre } & \multicolumn{3}{|c|}{ Geral } \\
\hline Hortaliça & Vol(a) & $\%(b)$ & Hortaliça & Vol & $\%$ & Hortaliça & Vol & $\%$ & Hortaliça & Vol & $\%$ \\
\hline Tomate & 4,8 & 21,8 & Melancia & 3,6 & 30,8 & Melancia & 0,6 & 63,8 & Tomate & 7,9 & 23,2 \\
\hline Cebola & 4,5 & 20,4 & Tomate & 3,0 & 25,7 & Milho Verde & 0,9 & 9,8 & Melancia & 6,6 & 19,5 \\
\hline Batata Ing | & 3,5 & 16,1 & Repolho & 1,3 & 10,7 & Tomate & 0,8 & 8,5 & Cebola & 4,9 & 14,4 \\
\hline Melancia & 2,4 & 11,0 & Cenoura & 0,9 & 8,1 & Abobrinha & 0,4 & 4,3 & Batata Ingl & 4,3 & 12,6 \\
\hline Repolho & 1,7 & 7,9 & Batata Ing I & 0,8 & 6,4 & Jiló & 0,4 & 4,3 & Repolho & 3,0 & 8,8 \\
\hline Abóbora & 1,6 & 7,5 & Pepino & 0,6 & 5,3 & Quiabo & 0,4 & 3,8 & Cenoura & 2,5 & 7,3 \\
\hline Cenoura & 1,5 & 7,0 & Chuchu & 0,4 & 3,6 & Feijão Vag & 0,2 & 2,1 & Abóbora & 1,6 & 4,8 \\
\hline Pepino & 0,8 & 3,5 & Abobrinha & 0,4 & 3,4 & Berinjela & 0,1 & 1,3 & Pepino & 1,4 & 4,1 \\
\hline Beterraba & 0,7 & 3,2 & Cebola & 0,4 & 3,4 & Chuchu & 0,1 & 1,1 & Beterraba & 0,9 & 2,8 \\
\hline Chuchu & 0,4 & 1,6 & Quiabo & 0,3 & 2,5 & Cebola & 0,1 & 1,1 & Chuchu & 0,8 & 2,3 \\
\hline Total & 22,0 & 100 & & 11,7 & 100 & & 0,9 & 100 & & 33,8 & 100 \\
\hline$\%$ & 64,8 & & & 34,5 & & & 2,8 & & & 100 & \\
\hline
\end{tabular}

(a) Volume comercializado pelos equipamentos em toneladas. (Commercialized volume at tonnes on the establishments); ${ }^{(b)}$ Porcentagem relativa de participação no volume comercializado. (Relative percentage on commercialized volume)

para elevar os preços e prejudicar a qualidade pós-colheita dos produtos. Duarte \& Andrade Júnior (2003) verificaram que a elevação do preço do melão no Piauí, provavelmente, teve relação com a importação deste produto de outros estados da região Nordeste.

Não há relatos sobre o mercado local de olerícolas para o município de Mineiros, nem os varejistas e olericultores locais têm conhecimento do que é consumido de hortaliças no município. Informações geradas por estudos mercadológicos são importantes para a olericultura e mercado locais e servem como parâmetros para elaboração de estratégias objetivando o fortalecimento do comércio de olerícolas que, conseqüentemente, produziria efeitos positivos como diminuição dos preços ao consumidor final, melhores preços pagos ao olericultor, facilitações do processo de transporte e logística de comercialização (menores distâncias).

Este trabalho teve como objetivo realizar o levantamento de informações de mercado de olerícolas comercializadas in natura em Mineiros-GO para fornecer suporte às ações e estratégias futuras de estruturação do setor.

\section{MATERIAL E MÉTODOS}

A pesquisa foi realizada no município de Mineiros localizado no sudoeste de Goiás às margens da rodovia BR-364 à 108 km a leste do município de Jataí-GO e a 90 $\mathrm{km}$ a oeste do município de Santa Rita do Araguaia-GO. Mineiros possui uma população de 43.961 pessoas, conforme estimativa realizada para o primeiro semestre de julho de 2005 do Instituto Brasileiro de Geografia e Estatística (IBGE, 2006a). Apresenta solos predominantemente arenosos e clima definido basicamente por duas estações: uma seca com temperaturas amenas e a outra chuvosa com temperaturas elevadas, apresentando como predominância vegetacional o Cerrado. É um município que apresenta como atividade principal a agropecuária baseada na exploração de culturas anuais como soja e milho e da pecuária de corte e leite.

Os estabelecimentos responsáveis pela comercialização de produtos hortifrutícolas em Mineiros são supermercados, quitandas/sacolões e feira-livre; classificação esta seguindo proposta de Barros et al. (1978), citados por Silva et al. (2003). O estudo foi composto pelos principais equipamentos varejistas, sendo oito supermercados de médio a pequeno porte, duas quitandas (conhecidas localmente como "frutarias") e uma feira-livre contendo feirantes.

A metodologia utilizada foi mediante visitação in loco para aplicação de questionário nos equipamentos varejistas no período compreendido entre dezembro de 2005 e janeiro de 2006. Foram realizadas entrevistas com os encarregados do setor de hortifruti (no caso dos supermercados), com os proprietários das quitandas/sacolões e diretamente com os feirantes nas bancas ou barracas de venda da feira-livre. O questionário foi elaborado de modo que os entrevistados respondessem aos objetivos da pesquisa e aplicado pela equipe de entrevistadores do Instituto de Dados Estatísticos e de Pesquisas Sócio-Econômicas (Indep) pertencente às Faculdades Integradas de Mineiros mantidas pela Fun- dação Integrada Municipal de Ensino Superior (Fimes) de Mineiros-GO.

O questionário foi constituído de questões (perguntas ao entrevistado) para obter as seguintes informações:

a) Hortaliças comercializadas semanalmente em maior volume;

b) Fornecedores das principais olerícolas comercializadas;

c) Preço médio de compra e venda.

A partir dos preços obtidos foi calculada a margem de comercialização utilizando-se a expressão proposta por Bueno et al. (1999):

$M v=\frac{P v-P a}{P v} \times 100$, onde:

$\mathrm{Mv}=$ margem do varejista; $\mathrm{Pv}=$ preço de venda no varejo; $\mathrm{Pa}=$ preço de venda no atacado.

Os Preços foram obtidos através de suas médias determinadas através do preço médio de venda e compra no mercado varejista de Mineiros e corrigidos pelo Índice Geral de Preços - IGP-DI para valores do primeiro semestre de 2006, conforme dados do Instituto Brasileiro de Economia (IBRE, 2006).

\section{RESULTADOS E DISCUSSÃO}

As principais hortaliças comercializadas em Mineiros são tomate, melancia, cebola e batata inglesa (Tabela 1). Isto demonstra que o município segue a tendência nacional onde estas quatro olerícolas são as comercializadas e produzidas em maior volume (Bononi, 2005; IBGE, 2006b). O destaque é a melancia que ocupou a $2^{\mathrm{a}}$ posição no ranking em Mineiros, demonstrando a maior preferência do 
consumidor por esta olerícola fruto. Isto contrasta com o mercado nacional onde a melancia ocupa a $4^{\mathrm{a}}$ posição em volume produzido e comercializado. Merece destaque também o repolho, pois esta hortaliça folhosa ocupou o posto de $5^{\text {a }}$ olerícola comercializada em maior volume semanal (Tabela 1).

Comparando-se os equipamentos varejistas, observou-se que os supermercados e quitandas são os principais canais de comercialização de produtos olerícolas em Mineiros (Tabela 1). É relevante considerar a importância das quitandas, pois estas são grandes canais de distribuição de hortaliças in natura no município. Para Silva et al., (2003), as quitandas (sacolões) são estabelecimentos comerciais especializados em hortifrutigranjeiros e os consumidores muitas vezes preferem buscar os seus produtos nestes locais à procura de qualidade e diversidade. Lourenzani \& Silva (2004) destacaram o crescimento deste agente de comercialização de hortaliças na preferência do consumidor.

Houve certa similaridade entre os principais produtos olerícolas comercializados entre supermercados e quitandas; já na feira-livre, houve certa diversificação, pois produtos como milho verde, jiló, feijãovagem e berinjela apareceram no ranking dos comercializados em maior volume no mercado livre e batata inglesa não aparece neste mercado. Isso pode ser explicado pelo fato deste canal de comercialização ter como principal fornecedor o olericultor local (Silva et al.; 2003), possibilitando assim maior diversificação de produtos conforme disponibilização de hortaliças nas hortas locais e exigências especiais do consumidor. A fraca participação da feira-livre no mercado de hortaliças em Mineiros pode ser reflexo da pequena presença da atividade olerícola no município e proximidades, pelo incipiente hábito dos mineirenses em adquirir os produtos olerícolas neste local e pelo fato da feira-livre ser realizada em apenas uma oportunidade, aos domingos no período matutino. A feira-livre tem como característica básica a comercialização de agro-alimentos produzidos nas propriedades rurais e áreas vizinhas com o feirante realizando compras diretas do produtor (às vezes é a mesma pessoa) (Silva et al., 2003). A presente pesquisa ainda revelou que $100 \%$ das hortaliças frescas comercializados na feira-livre são oriundas de hortas locais (Tabela 2).

Embasado nos preços de compra (atacado) e de venda (varejo) dos prin-

Tabela 2. Principais fornecedores de olerícolas comercializadas semanalmente em toneladas nos equipamentos varejistas de Mineiros-GO. (Main vegetable furnishers at the retail establishments on weekly commercialization at tonnes in city Mineiros-GO). ICA/Fimes, Mineiros, 2006.

\begin{tabular}{lcccccccc}
\hline \multirow{2}{*}{ Fornecedores } & \multicolumn{9}{c}{ Equipamentos } & \multirow{2}{*}{ Geral } \\
\cline { 2 - 7 } & \multicolumn{3}{c}{ Supermercados } & \multicolumn{2}{c}{ Quitandas } & Feira-livre & & \\
\hline Ceasa-GO & 16,4 & $75,0^{(a)}$ & 11,7 & 100 & - & - & 26,2 & 72,7 \\
Produtores Locais & 2,7 & 12,5 & - & - & 1,1 & 100 & 6,6 & 18,2 \\
Ceasa-SP & 2,7 & 12,5 & - & - & - & - & 3,3 & 9,1 \\
\hline & $21,9^{(b)}$ & 100 & 11,7 & 100 & 1,1 & 100 & $36,1^{(\text {(c) }}$ & 100 \\
\hline
\end{tabular}

(a)Porcentagem relativa de participação no volume total comercializado. (Relative percentage on

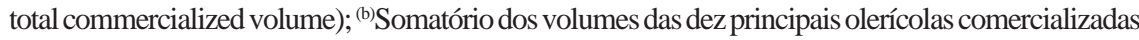
por equipamento. (Volume total of the ten main vegetables commercialized per establishment); ${ }^{(c)}$ Somatório dos volumes das dez principais olerícolas comercializadas em todos os equipamentos entrevistados (33,8 t) e das demais olerícolas (2,3 kg). (Volume total of the ten main vegetables commercialized overall establishments (33.8 ton) added to other vegetables (2.3 ton).

Tabela 3. Margem de comercialização conforme os preços no atacado e varejo das principais olerícolas frescas comercializadas nos equipamentos de Mineiros-GO. (Margin commercialization according to wholesale and retail prices of the main fresh vegetables on establishments in city Mineiros). ICA/Fimes, Mineiros, 2006.

\begin{tabular}{lccc}
\hline Hortaliça (a) & Margem (\%) & Preço no atacado ${ }^{(\mathbf{b}, \mathbf{1})}$ & Preço no varejo ${ }^{(\mathbf{c}, \mathbf{1})}$ \\
\hline Tomate & 38,44 & 1,01 & 1,64 \\
Cebola & 33,39 & 0,85 & 1,28 \\
Pepino & 30,22 & 0,94 & 1,35 \\
Repolho & 29,79 & 0,64 & 0,91 \\
Beterraba & 28,77 & 1,01 & 1,42 \\
Cenoura & 28,31 & 1,06 & 1,48 \\
Melancia & 23,21 & 0,49 & 0,64 \\
Chuchu & 20,74 & 1,18 & 1,49 \\
Abóbora & 17,58 & 0,96 & 1,16 \\
Batata Inglesa & 15,45 & 1,43 & 1,69
\end{tabular}

(a) Ordenação conforme preço no varejo. (Ordinance according to retail price); (b)Preço médio de compra nos fornecedores em $\mathrm{R} \$ \mathrm{Kg}^{-1}$. (Average purchase price on the furnishers at $\mathrm{R} \$$ $\mathrm{Kg}^{-1}$ ); (c)Preço médio de venda ao consumidor em $\mathrm{R} \$ \mathrm{Kg}^{-1}$. (Average sale price to consumer at $\left.\mathrm{R} \$ \mathrm{~kg}^{-1}\right)$; ${ }^{(1)}$ Preço corrigido pelo IGP-DI mediante fator de correção referente à participação do mês de maio no ano conforme IEA (2006). (Price adjustment by IGP-DI through correcting factor in relation to May participation on the year according to IEA, 2006).

cipais produtos olerícolas dos equipamentos envolvidos neste trabalho, observou-se que batata inglesa e tomate foram as mais onerosas para o consumidor final. As margens de comercialização das diferentes hortaliças demonstraram considerável variação. Os valores oscilaram de 38,44\% a 15,45\% (Tabela 3). Bueno et al. (1999) explicaram que as margens de comercialização oscilam devida a tendência de manutenção dos preços no varejo mesmo com a sazonalidade destes no atacado. As margens apresentadas pelos equipamentos envolvidos a presente revelaram que estas podem ser trabalhadas para incentivar maior consumo de determinadas hortaliças. Atuando, por exemplo, com margens menores para pepino e beterraba e maior para batata inglesa, ou seja, realizar preços promocionais para os dois primeiros produtos e compensar a perda na margem de comercialização geral no pre- ço da batata, pois esta é comercializada em grande volume e um pequeno acréscimo, praticamente, seria desapercebido e contribuiria para a manutenção da margem de lucro do setor hortifrutícola do equipamento varejista. Rangel et al. (2003) mencionaram que o preço é um dos principais critérios adotados pelos consumidores na decisão de qual produto vegetal consumir. Para Lourenzani e Silva (2004) a criação de dias promocionais é uma excelente forma de atrair o consumidor.

O preço de cada hortaliça nos mercados hortifrutícolas tem tendência de apresentar relação inversa com o volume comercializado ao consumidor final (Rangel et al., 2003; Lourenzani \& Silva, 2004). Embora esta relação não tenha sido percebida visualmente no presente trabalho (Tabela 1 e 3), mediante análise de correlação pôde-se observar que houve correlação negativa significativa entre estes dois parâmetros (Tabela 4). 
Tabela 4. Coeficientes de correlação simples entre volume de olerícolas comercializado semanalmente e preços praticados no mercado. (Simple relationship coefficient between vegetable volume commercialized weekly and prices on retail). ICA/Fimes, Mineiros, 2006.

\begin{tabular}{lcc}
\hline Parâmetros & Coeficiente de correlação & Probabilidade $>\mathbf{t}^{(1)}$ \\
\hline Volume $\times$ Preço varejo & $-0,13$ & 0,00182 \\
Preço atacado $\times$ Preço varejo & 0,91 & 0,00002 \\
\hline
\end{tabular}
(1) $\mathrm{P}>0,05$.

A comprovação de que Mineiros e regiões próximas são incapazes de abastecer o mercado interno de olerícolas ficou evidenciada quando se obteve uma participação de $81,8 \%$ de atacados distantes no fornecimento das hortaliças ao município; apenas $18,2 \%$ do produto eram fornecidos por produtores locais (Tabela 2). A distância entre mercados fornecedores e compradores (atacados e varejos) tem influência diretamente proporcional nos preços ofertados ao consumidor final (Duarte \& Andrade Júnior, 2003). A pequena participação dos produtores locais no fornecimento de hortaliças, aliada a pouca expressão do volume de vendas na feira-livre podem servir como parâmetros para comprovar a incipiente importância do agronegócio olericultura para Mineiros e proximidades. Mediante estes fatos, fica caracterizada a necessidade de se desenvolver e organizar o setor produtivo de olerícolas em Mineiros e região a fim de atender o mercado interno e, ao mesmo tempo, realizar um trabalho de valorização da feira-livre e dos produtos lá comercializados.

Os resultados obtidos pelo presente trabalho também demonstraram que os varejistas de Mineiros precisam ficar atentos às possibilidades de flexibilização das margens de comercialização e às possibilidades de oferecimentos de dias promocionais, pois a manipulação estratégica das margens de lucro poderia favorecer maior consumo de determinadas hortaliças pelo simples fato de seus preços sofrerem diminuição sem, porém, afetar significativamente o rendimento lucrativo das vendas.

As informações obtidas neste trabalho são de considerável relevância para os mercados varejistas do município de Mineiros, pois dão uma idéia do consumo semanal de olerícolas, relacionando-o com o preço praticado nos mercados atacadista e varejista. Isto possibilita, por exemplo, que um equipamento possa aumentar as vendas de determinados produtos mediante preços mais acessíveis obtidos por melhor manipulação das margens de comercialização, incentivando assim maior consumo destes vegetais pela população. Outra contribuição importante é o fato dos resultados terem evidenciado a necessidade dos equipamentos varejistas em vencer grandes distâncias para obtenção dos produtos olerícolas devida à pouca expressão do setor produtivo local, situação esta que deve ser encarada não somente como desvantajosa, mas também como forma de incentivo para investimentos no setor, pois se não há oferta é preciso criá-la embasando-se na idealização e implementação de programas de desenvolvimento do agronegócio olericultura local. O incentivo à olericultura local poderia, por exemplo, reduzir os preços pela redução dos custos de transporte.

Os resultados obtidos permitem concluir que em Mineiros-GO os supermercados são predominantes no volume de olerícolas comercializado; as quitandas são, proporcionalmente, importantes canais de comercialização de produtos olerícolas; a feira-livre é pouco participativa no mercado de hortaliças e é passível de ampliações, não só para beneficiar o consumidor final, mas também como forma de incentivo ao olericultor mineirense. A feira-livre pode ser uma forma interessante para incentivar o agronegócio olerícola e para isso é importante estruturar e ampliar a área de comercialização, bem como oferecer outros momentos para a realização da feiralivre. O mercado de hortaliças é dependente do abastecimento a longas distâncias, o que indica o pouco desenvolvimento da olericultura local.

\section{AGRADECIMENTOS}

Os autores agradecem ao FIMES pelo apoio na execução do presente trabalho.

\section{REFERÊNCIAS}

AGRIANUAL - Anuário da Agricultura Brasileira. 2000. São Paulo: FNP. p.49-50.

BONONI G. 2005. Ceagesp: gigante dos hortifrutigranjeiros e palco dos pequenos. A Granja 684: 50-55.

BUENO CR; REIS RP; SOUZA M. 1999. Estudo mercadológico da sazonalidade de frutos cítricos ofertados no município de Lavras-MG. Ciência e Agrotecnologia 23: 813-824.
CAMARGOFILHOWP; MAZZERAR;ALVESHS. 2001. Mercado de raízes e tubérculos: análise de preços. Informações Econômicas 31: 36-44.

CAMPOS FM; PINHEIRO-SANT'ANA HM; SOUZA PM; STRINGHETA PC; CHAVES JBP. 2006. Pró-vitaminas a em hortaliças comercializadas no mercado formal e informal de Viçosa (MG), em três estações do ano. Ciência e Tecnologia de Alimentos 26: 33-40.

DUARTE RLR; ANDRADE JÚNIOR AS. 2003. Estudo da oferta e comercialização de melão na Ceasa-PI (1991-1996). Horticultura Brasileira 21: 127-131.

EMBRAPA - Empresa Brasileira de Pesquisa Agropecuária. 2006, 23 de julho. Hortaliças em números: produção, 1980-2004. Disponível em: http://www.cnph.embrapa.br/paginas/ hor t a l i ca s_e m_ n u m e r o s/ hortalicas_em_numeros.htm

FAGUNDES GR; YAMANISHI OK. 2002. Estudo da comercialização do mamão em Brasília-DF. Revista Brasileira de Fruticultura 24: 91-95.

FARINA EMMQ; MACHADO EL. 1999. Government regulation and business strategies in the Brazilian fresh fruit and vegetable market. In: WORKSHOP BRASILEIRO DE GESTÃO DE SISTEMAS AGROALIMENTARES, 2. Anais... Ribeirão Preto: Pensa/FEA/USP. p.267-275.

FILGUEIRA FAR. 2003. Manual de olericultura: agrotecnologia moderna na produção e comercialização de hortaliças. Viçosa: UFV. 412p.

FAO. Food and Agriculture Organization of the United Nations. 2007, 10 de agosto. Faostat database: core consumption data. Disponível em http://faostat.fao.org/default.aspx

IBRE - Instituto Brasileiro de Economia. 2006, 18 de julho. Índice Geral de Preços: IGP-DI. Fundação Getúlio Vargas/IBRE. Disponível em: http:// www2.fgv.br/noticias_internet/ARQ/6438.PDF

IBGE - Instituto Brasileiro e Geografia e Estatística. 2006a, 13 jullho. Estimativas de população. Disponível em: ftp://ftp.ibge.gov.br/ Estimativas_Projecoes_Populacao/Estimativas_2005/UF_Municipio.zip

IBGE - Instituto Brasileiro de Geografia e Estatística. 2006b, 13 de julho. Sidra: Sistema IBGE de recuperação automática. Disponível em: http://www.sidra.ibge.gov.br

LOURENZANI AEBS; SILVAAL. 2004. Um estudo da competitividade dos diferentes canais de distribuição de hortaliças. Gestão e Produção 11: 385-398.

RANGEL SB; FAGUNDES GR; FALCÃO TCC; MENDES RS; YAMANISHI OK. 2003. Perfil do mercado varejista e consumidor de mamão dos grupos 'solo' e 'formosa' do Distrito Federal-DF. Revista Brasileira de Fruticultura 25: 85-88.

SILVA CRM; NAVES MMV. 2001. Suplementação de vitaminas na prevenção de câncer. Revista de Nutrição 14: 135-143.

SILVACS; PEROSAJMY; RUAPS; ABREU CLM; PÂNTANO SC; VIEIRA CRYI; BRIZOLA RMO. 2003. Avaliação econômica das perdas de banana no mercado varejista: um estudo de caso. Revista Brasileira de Fruticultura 25: 229-234.

VILELA NJ; LANA MM; NASCIMENTO EF; MAKISHIMA N. 2003. Perdas na comercialização de hortaliças em uma rede varejista do Distrito Federal. Cadernos de Ciência e Tecnologia 20: 521-541. 